\title{
Cold water swimming and upper respiratory tract infections
}

\author{
Naomi Collier ${ }^{1 *}$, Heather C Massey ${ }^{1}$, Mitch Lomax ${ }^{1}$ Mark Harper ${ }^{2}$, Michael J Tipton ${ }^{1}$ \\ From 15th International Conference on Environmental Ergonomics (ICEE XV) \\ Portsmouth, UK. 28 June - 3 July 2015
}

\begin{abstract}
Introduction
It is often suggested that habitual cold water swimming (HCS) may improve resistance to infection [1], yet research into effects of HCS on the immune system has produced inconclusive results. This may be due to the wide range of protocols, from brief ice-cold dips [2] to long cold water swims [3]. Many studies measured blood and saliva markers rather than actual illness, and the clinical significance of these markers is not well established [4]. Incidence of upper respiratory tract infection (URTI), i.e. the common cold, is a useful indication of in vivo immune system function $[5,6]$. This study compared URTI susceptibility in those practising HCS with that in their non-swimming co-habiting partners. To control for any effect of swimming, those who swim in indoor heated pools and their partners were also investigated. The null hypothesis $\left(\mathrm{H}_{0}\right)$ was that there would be no difference between swimming groups.
\end{abstract}

\section{Methods}

50 couples were recruited to this ethically approved study, with 44 completing it: 21 cold water swimmers, 23 pool swimmers, and their non-swimming partners. Participants reported URTI symptoms using the Jackson Cold Scale [7], and their physical activity (PA), every week for 13 weeks from 1 December 2014. URTI frequency and severity were calculated per group each week. Each person's symptom days were weighted for severity and totalled. The sum of scores $\geq 14$ was divided by the number of responses to give URTI frequency, and by the number of persons scoring $\geq 14$ to give URTI severity. Group averages for the 13 weeks were compared between all groups ( $\mathrm{t}$-test for independent

\footnotetext{
* Correspondence: naomi.collier@port.ac.uk

'Extreme Environments Laboratory, Department of Sport and Exercise

Science, University of Portsmouth, Portsmouth, UK

Full list of author information is available at the end of the article
}

samples or Mann-Witney U) and correlations were sought between PA and URTI measures (Pearson's $r$ or Spearman's $\rho$ ).

\section{Results}

Cold swimmers had fewer colds than their partners (URTI frequency, mean (SD) $3.0(3.2)$ v 5.5 (3.2), p = 0.03 ; percent with URTI $8.2 \% \mathrm{v} 12.8 \%, \mathrm{p}=0.04)$. There were no statistically significant differences between cold and pool swimmers in any URTI measure. More pool partners than swimmers got an URTI $(17.8 \% \mathrm{v} 11.4 \%$, $\mathrm{p}=0.03)$. Cold partners had more severe colds than pool partners (URTI severity $41.6(17.1)$ v $29.7(8.2), \mathrm{p}=0.03)$. There were trends for correlations between weekly cold swim time and URTI rate (Spearman's $\rho=0.51$, $\mathrm{p}=0.07)$, and between weekly cold swim duration and URTI severity $(r=0.50, \mathrm{p}=0.09)$. There were no correlations between pool swimming and URTIs.

\section{Discussion}

Although cold water swimmers had the lowest average URTI frequency and the lowest percent with an URTI, these were only statistically significant when compared to cold partners. URTI severity was highest in cold partners and very similar in the other three groups. Both groups of swimmers had fewer URTIs than their partners, but this does not imply any protective effect of swimming, and in respect of cold water swimming it appears that more may not be better. These are preliminary results and deeper analysis is continuing.

\section{Conclusion}

There were no differences in URTI susceptibility between cold and pool swimmers $\left(\mathrm{H}_{0}\right.$ accepted), therefore cold water swimming appears to have no protective effect. Cold swimmers had better resistance to colds than their partners, but the reason for this is not known. 


\section{Authors' details}

${ }^{1}$ Extreme Environments Laboratory, Department of Sport and Exercise

Science, University of Portsmouth, Portsmouth, UK. ${ }^{2}$ Consultant Anaesthetist,

Royal Sussex County Hospital, Brighton, UK.

Published: 14 September 2015

\section{References}

1. Harper CM: Medical Hypotheses 2012, 78:516-519.

2. Dugué B, Leppänen E: Clinical Physiology 2000, 20(2):114-121.

3. Kormanovski A, Castañeda Ibarra F, Lara Padilla E, Campos Rodriguez R: International Journal of Medicine and Medical Sciences 2010, 2(3):80-87.

4. Gleeson M: J Appl Physiol 2007, 103:693-699.

5. Brenner IKM, Castellani JW, Gabaree C, Young AJ, Zamecnik J, Shephard RJ, Shek PN: J Appl Physiol 1999, 87:699-710.

6. Bishop NC, Gleeson M: Frontiers in Bioscience 2009, 14:4444-4456.

7. Barrett B, Brown R, Voland R, Maberry R, Turner R: Eur Respir J 2006, 28:358-363.

doi:10.1186/2046-7648-4-S1-A36

Cite this article as: Collier et al: Cold water swimming and upper respiratory tract infections. Extreme Physiology \& Medicine 2015 4(Suppl 1): A36.

Submit your next manuscript to BioMed Central and take full advantage of:

- Convenient online submission

- Thorough peer review

- No space constraints or color figure charges

- Immediate publication on acceptance

- Inclusion in PubMed, CAS, Scopus and Google Scholar

- Research which is freely available for redistribution

Submit your manuscript at www.biomedcentral.com/submit
(Ciomed Central 